\title{
Gerakan Kembali Ke Desa Melalui Peningkatan Keterampilan Masyarakat Desa Wisata Budaya
}

\author{
Tan Evan Tandiyono ${ }^{1 *}$, IGN Anom Maruta ${ }^{2}$, Fawwas Rahmatullah ${ }^{3}$, Dendi Arista Pratama ${ }^{4}$ \\ 1,2,3,4 Universitas 17 Agustus 1945 Surabaya/Fakultas Ekonomi \&Bisnis \\ e-mail: tan@untag-sby.ac.id ${ }^{1}$, anommaruta@untag-sby.ac.id ${ }^{2}$ \\ *Penulis Korespondensi: E-mail: tan@untag-sby.ac.id
}

\begin{abstract}
Villages often get a bad stigma in people's minds, because there is an old paradigm that the village is the most residential area and is an often-boring area. This often comes to mind among both young people and young workers. The glitter of the city often trumps the simplicity of the village, so the level of urbanization from village to city from year to year is increasing. As a result, the village became increasingly abandoned and the city became more and more full. The implementation of this community service activity is carried out using skill training methods. In the implementation, participants were given motivation to have awareness of the importance of improving skills for village development and the importance of building themselves to prepare roads to be ready to compete in the development of cultural tourism villages. In addition, the community is given trainings that can improve the skills of the community to prepare the village in welcoming the change into a cultural tourism village. This activity is centered in Plunturan Village so that the soul of cultural tourism village development can start from the village level and more and more hamlets are starting to rise to participate in the development of cultural tourism villages. Therefore, each participant is given training materials on creative business planning with the utilization of natural resources and the addition of practical skills, ranging from analyzing business opportunities to product determination, financial management, and village cultural marketing. The sustainable plan of this program is the establishment of a business based on the potential of the local area and the empowerment of local communities as well as the marketing of quality regional superior products and preserving local culture. Hopefully, the village's business results can reach national and international markets and become a plus to build the village.
\end{abstract}

Keywords: Back to Village Movement, Skills Improvement, Cultural Village, Tourism

\begin{tabular}{l} 
Abstrak \\
Desa seringkali mendapatkan stigma buruk di dalam benak masyarakat, karena terdapat \\
paradigma lama bahwa desa merupakan daerah tertingggal dan merupakan wilayah yang \\
seringkali membosankan. Hal ini seringkali muncul di dalam benak kalangan orang muda maupun \\
tenaga kerja muda. Gemerlap kota seringkali mengalahkan kesederhanaan desa, sehinggga tingkat \\
urbanisasi dari desa ke kota dari tahun ke tahun makin meningkat. Akibatnya, desa menjadi makin \\
ditinggalkan dan kota menjadi makin penuh. Pelaksanaan kegiatan pada pengabdian masyarakat \\
ini, dilakukan dengan menggunakan metode pelatihan keterampilan. Dalam pelaksanaannya, \\
peserta diberikan motivasi agar memiliki kesadaran akan pentingnya peningkatan keterampilan \\
bagi pengembangan desa dan pentingnya membangun diri untuk mempersiapkan jalan agar siap \\
bersaing dalam pengembangan desa wisata budaya. Selain itu, masyarakat diberikan pelatihan- \\
pelatihan yang dapat meningkatkan keterampilan masyarakat untuk mempersiapkan desa dalam \\
menyambut perubahan menjadi desa wisata budaya. Kegiatan ini dipusatkan di Desa Plunturan \\
sehingga jiwa pengembangan desa wisata budaya dapat dimulai dari tingkat desa dan makin \\
banyak dusun yang mulai bangkit untuk berpartisipasi dalam pengembangan desa wisata budaya. \\
Oleh karena itu, setiap peserta diberikan materi pelatihan tentang perencanaan usaha kreatif \\
dengan pemanfaatan sumber daya alam dan penambahan keterampilan-keterampilan praktis, \\
mulai dari menganalisa peluang usaha sampai dengan penentuan produk, pengelolaan keuangan, \\
serta pemasaran budaya desa. Rencana berkelanjutan dari program ini adalah terbentuknya usaha \\
yang berdasarkan potensi daerah lokal dan pemberdayaan masyarakat setempat serta pemasaran \\
produk unggulan daerah yang berkualitas serta melestarikan kebudayaan lokal. Harapannya, hasil \\
\hline
\end{tabular}


usaha desa tersebut bisa mencapai pasar nasional dan internasional serta menjadi nilai tambah untuk membangun desa.

Kata Kunci : Gerakan Kembali ke Desa, Peningkatan Keterampilan, Desa Budaya, Wisata

\section{PENDAHULUAN}

Desa Plunturan, kec Pulung Kabupaten Ponorogo merupakan wilayah yang memiliki berbagai produk budaya. Produk budaya tersebut diantaranya adalah : Reyog yang terdiri atas : reyog anak, reyog perempuan dan reyog taruna; Gajah-gajahan; Jathilan; Ganongan; Tledekan; Karawitan; Wayang kulit; Coke'an; Metik desa; Metri tandur; Campursari; Sego Angkruk. Berbagai produk budaya tersebut telah menjadi ciri khas masyarakat plunturan sebagai desa yang kaya akan seni tradisional yang masih dipertahankan hingga saat ini.

Namun yang menjadi problem adalah jumlah kelompok pelaku seni yang masih mempertahankan budaya kesenian daerah yang telah menjadi ciri khas Ponorogo tersebut ternyata tidaklah banyak. Berdasarkan data, ternyata kelompok pelaku seni yang ada di Ponorogo tidaklah banyak jumlahnya. Bahkan untuk beberapa kategori, malahan terlihat hanya menyisakan 1 kelompok masyarakat saja yang masih mempertahankannya. Apa yang akan terjadi ketika semua yang ada dikelompok tersebut telah lanjut usia dan tidak ada regenerasi kelompok baru atau usia muda ? maka sudah tentu seni budaya tersebut akan punah karena tidak adanya generasi pelestari yang baru.

Namun belakangan ini mulai muncul semangat baru dari kelompok masyarakat, terutama mereka yang berada di Desa Plunturan, Kecamatan Pulung, Kabupaten Ponorogo yang mendeklarasikan diri untuk mau memulai langkah maju dalam mengembangkan desa wisata budaya di wilayah tersebut agar dapat terciptanya lingkungan budaya yang kondusif bagi pengembangan dan pelestarian kebudayaan khas Ponorogo tersebut.

Hal ini mulai diperlihatkan dengan mulai masifnya usaha sosialisasi dan promosi kepada masyarakat lokal untuk mulai memperkenalkan kebudayaan asli Ponorogo dengan diadakannya Gelaran Kesenian Budaya setiap tahun. Namun hal ini ternyata masih dirasa kurang, karena keterbatasan kemampuan dalam pengolahan sumber daya alam dan keterampilan sumber daya manusia diberbagai aspek. Selain itu, kelompok masyarakat pelestari budaya mengalami kendala akibat serangan massif dari budaya asing nan modern yang mulai menggerus minat kaum muda taruna untuk menggeluti dunia seni budaya lokal yang dirasa sangat kuno dan jadul. Hal ini menjadi keprihatinan tersendiri bagi mereka penggiat kesenian daerah dalam melakukan regenerasi penerus pelestari budaya kesenian daerah khas Ponorogo tersebut. Oleh karena itu, mereka sangat pengharapkan bantuan dari pihak luar yang juga menaruh perhatian dalam pengembangan dan pelestarian kebudayaan khas daerah agar dapat menemukan solusi yang tepat dan benar.

Disisi lain, Kepunahan kebudayaan sudah ada didepan mata dan saat ini sedang dikejar oleh waktu sebelum kepunahan itu tiba. Kepunahan kebudayaan adalah sebuah akhir dari fase sebuah keadaan yang mulai dapat dirasakan saat ini. Dari yang semula ada menjadi tiada atau sirna, dari yang lahir kemudian menjadi hilang tanpa jejak, atau tergantikan oleh yang baru sehingga yang lama disingkirkan (dilupakan). Dalam beberapa aspek, kepunahan kebudayaan sering kali diidentikkan kerena ketiadaan peran (terutama mereka yang berkepentingan dan memegang kekuasaaan serta memiliki pengetahuan lebih) yang menjaga hal-hal yang seharusnya diharapkan agar dapat tetap bertahan hidup atau eksis di tengah penggerusan jaman oleh budaya asing yang menggantikan budaya lokal.

Oleh karena itu, pengabdian masyarakat ini terasa begitu urgensinya, sehingga 
merasa perlu untuk dilakukan secepat mungkin dalam melakukan gerakan aktif secara menyeluruh dan mendalam agar dimulainya arah pengembangan desa melalui gerakan kembali ke desa dengan melakukan peningkatan kapasitas keterampilan sumber daya manusia masyarakat desa sehingga dapat terwujudnya cita-cita pengembangan desa wisata budaya di Desa Plunturan, Kecamatan Pulung, Kabupaten Ponorogo.

\section{METODE PELAKSANAAN}

Melalui pendahuluan diatas, maka berikut adalah metode pelaksanaan yang ingin dicapai dari pengabdian masyarakat yang telah di laksanakan di Desa Plunturan, Kecamatan Pulung, Kabupaten Ponorogo, sebagai berikut :

Tabel 1. Metode Pelaksanaan

\begin{tabular}{|c|c|c|c|c|}
\hline No & Kelompok Budaya & Kegiatan & Permasalahan & Target Solusi \\
\hline 1 & $\begin{array}{l}\text { Kesenian Tari } \\
\text { Reyog, Jathilan, } \\
\text { Gajah-gajahan, } \\
\text { Genongan, dan } \\
\text { Tledekan. }\end{array}$ & Regenerasi & $\begin{array}{l}\text { Tidak adanya } \\
\text { perencanaan } \\
\text { program } \\
\text { regenerasi yang } \\
\text { konkrit untuk } \\
\text { jangka pendek, } \\
\text { menengah, dan } \\
\text { panjang. }\end{array}$ & $\begin{array}{l}\text { Merumuskan dan } \\
\text { mencetuskan } \\
\text { program regenerasi } \\
\text { yang konkrit untuk } \\
\text { jangka pendek, } \\
\text { menengah, dan } \\
\text { panjang. }\end{array}$ \\
\hline 2 & $\begin{array}{l}\text { Kesenian Tari } \\
\text { Reyog, Jathilan, } \\
\text { Gajah-gajahan, } \\
\text { Genongan, dan } \\
\text { Tledekan. }\end{array}$ & $\begin{array}{l}\text { Promosi } \\
\text { Budaya }\end{array}$ & $\begin{array}{l}\text { Kurang } \\
\text { kreatifnya } \\
\text { promosi budaya } \\
\text { membuat } \\
\text { kebudayaan khas } \\
\text { daerah menjadi } \\
\text { kurang menarik } \\
\text { dan } \\
\text { membosankan. }\end{array}$ & $\begin{array}{l}\text { Memberikan } \\
\text { pelatihan kepada } \\
\text { kaum muda dan } \\
\text { taruna agar } \\
\text { berperan aktif } \\
\text { dalam ikut ambil } \\
\text { bagian dalam } \\
\text { mempromosikan } \\
\text { budaya daerah } \\
\text { melalui berbagai } \\
\text { macam jenis media } \\
\text { yang tersedia. }\end{array}$ \\
\hline 3 & $\begin{array}{l}\text { Kesenian Alat } \\
\text { Musik Karawitan } \\
\text { dan Coke'an }\end{array}$ & $\begin{array}{l}\text { Kurikulum } \\
\text { Pembelajaran } \\
\text { dan Pelatihan }\end{array}$ & $\begin{array}{l}\text { Tidak adanya } \\
\text { kurikulum } \\
\text { pembelajaran dan } \\
\text { pelatihan yang } \\
\text { jelas sehingga } \\
\text { menyebabkan } \\
\text { kesenian musik } \\
\text { karawitan dan } \\
\text { coke'an menjadi } \\
\text { sulit untuk } \\
\text { dipelajari dan } \\
\text { kurang menarik } \\
\text { minat dalam } \\
\text { mempelajari. }\end{array}$ & $\begin{array}{l}\text { Merumuskan dan } \\
\text { mencetuskan } \\
\text { kurikulum } \\
\text { pendidikan } \\
\text { kesenian musik } \\
\text { karawitan dan } \\
\text { coke'an sehingga } \\
\text { mudah untuk } \\
\text { dipahami dan } \\
\text { terdapat sasaran } \\
\text { target pencapaian } \\
\text { yang jelas serta } \\
\text { pendidikan } \\
\text { kesenian yang } \\
\text { mudah untuk } \\
\text { dipelajari. }\end{array}$ \\
\hline 4 & $\begin{array}{l}\text { Kesenian Peran } \\
\text { Wayang Kulit }\end{array}$ & $\begin{array}{l}\text { Kurikulum } \\
\text { Pembelajaran } \\
\text { dan Pelatihan }\end{array}$ & $\begin{array}{l}\text { Tidak adanya } \\
\text { kurikulum } \\
\text { pembelajaran } \\
\text { dan pelatihan }\end{array}$ & $\begin{array}{l}\text { Merumuskan dan } \\
\text { mencetuskan } \\
\text { kurikulum } \\
\text { pendidikan kesenian }\end{array}$ \\
\hline
\end{tabular}




\begin{tabular}{|c|c|c|c|c|}
\hline No & Kelompok Budaya & Kegiatan & Permasalahan & Target Solusi \\
\hline & & & $\begin{array}{l}\text { yang jelas } \\
\text { sehingga } \\
\text { menyebabkan } \\
\text { kesenian peran } \\
\text { wayang kulit } \\
\text { menjadi sulit } \\
\text { untuk dipelajari } \\
\text { dan kurang } \\
\text { menarik minat } \\
\text { dalam } \\
\text { mempelajari. }\end{array}$ & $\begin{array}{l}\text { peran wayang kulit } \\
\text { sehingga mudah } \\
\text { untuk dipahami dan } \\
\text { terdapat sasaran } \\
\text { target pencapaian } \\
\text { yang jelas serta } \\
\text { pendidikan kesenian } \\
\text { yang mudah untuk } \\
\text { dipelajari. }\end{array}$ \\
\hline 5 & $\begin{array}{l}\text { Kesenian Musik } \\
\text { Campur Sari }\end{array}$ & $\begin{array}{l}\text { Kurikulum } \\
\text { Pembelajaran } \\
\text { dan Pelatihan }\end{array}$ & $\begin{array}{l}\text { Tidak adanya } \\
\text { kurikulum } \\
\text { pembelajaran } \\
\text { dan pelatihan } \\
\text { yang jelas } \\
\text { sehingga } \\
\text { menyebabkan } \\
\text { kesenian musik } \\
\text { campur sari } \\
\text { menjadi sulit } \\
\text { untuk dipelajari } \\
\text { dan kurang } \\
\text { menarik minat } \\
\text { dalam } \\
\text { mempelajari. }\end{array}$ & $\begin{array}{l}\text { Merumuskan dan } \\
\text { mencetuskan } \\
\text { kurikulum } \\
\text { pendidikan kesenian } \\
\text { musik campur sari } \\
\text { sehingga mudah } \\
\text { untuk dipahami dan } \\
\text { terdapat sasaran } \\
\text { target pencapaian } \\
\text { yang jelas serta } \\
\text { pendidikan kesenian } \\
\text { yang mudah untuk } \\
\text { dipelajari. }\end{array}$ \\
\hline 6 & $\begin{array}{l}\text { Upacara AdaMetik } \\
\text { Desa dan Metri } \\
\text { Tandur }\end{array}$ & $\begin{array}{l}\text { Organizer } \\
\text { dan Promosi } \\
\text { Gelaran } \\
\text { Budaya }\end{array}$ & $\begin{array}{l}\text { Organizer yang } \\
\text { tidak teratur dan } \\
\text { pengaturan yang } \\
\text { asal-asalan } \\
\text { menyebabkan } \\
\text { upacara adat } \\
\text { menjadi kurang } \\
\text { menarik dan } \\
\text { kurang menjual } \\
\text { sehingga tidak } \\
\text { banyak } \\
\text { pendatang yang } \\
\text { tertarik untuk } \\
\text { melihat. Belum } \\
\text { lagi tidak adanya } \\
\text { promosi yang } \\
\text { kreatif } \\
\text { menyebabkan } \\
\text { kurang menarik } \\
\text { minat wisata } \\
\text { lokal maupun } \\
\text { mancanegara. }\end{array}$ & $\begin{array}{l}\text { Melakukan pelatihan } \\
\text { keterampilan } \\
\text { organizer upacara } \\
\text { adat yang } \\
\text { professional } \\
\text { sehingga setiap } \\
\text { upacara adat dapat } \\
\text { berjalan dengan } \\
\text { penuh kesakralan } \\
\text { dan memiliki nilai } \\
\text { seni yang tinggi } \\
\text { dimata mereka yang } \\
\text { datang untuk } \\
\text { menyaksikannya. } \\
\text { Promosi gelaran } \\
\text { budaya maupun } \\
\text { upacara adat yang } \\
\text { masif dan } \\
\text { terstruktur sehingga } \\
\text { dapat mengundang } \\
\text { banyak tamu lokal } \\
\text { maupun } \\
\text { mancanegara. }\end{array}$ \\
\hline 7 & Tour Guide & $\begin{array}{l}\text { Pelayanan } \\
\text { Prima }\end{array}$ & $\begin{array}{l}\text { Agar kebudayaan } \\
\text { daerah bisa } \\
\text { disajikan dalam } \\
\text { bentuk satu paket }\end{array}$ & $\begin{array}{l}\text { Mendokumentasikan } \\
\text { dan menstruktur } \\
\text { kebudayaan. Setiap } \\
\text { pemandu yang }\end{array}$ \\
\hline
\end{tabular}




\begin{tabular}{|c|l|l|l|l|}
\hline No & Kelompok Budaya & Kegiatan & Permasalahan & \multicolumn{1}{|c|}{ Target Solusi } \\
\hline & & & maka diperlukan & ditugaskan harus \\
& & & $\begin{array}{l}\text { pemandu yang bisa } \\
\text { membawa tamu } \\
\text { mempelajari dan } \\
\text { menguasai }\end{array}$ & berkeliling dari \\
pengetahuan dan \\
\end{tabular}

(Sumber: Pelaksana kegiatan)

\section{HASIL dan PEMBAHASAN}

Pelaksanaan kegiatan menjelaskan tahapan atau langkah-langkah yang telah dilakukan untuk mengatasi permasalahan, yang memuat hal-hal berikut ini :

Tabel 2. Pelaksanaan Kegiatan

\begin{tabular}{|c|c|c|c|c|}
\hline No & $\begin{array}{c}\text { Kelompok } \\
\text { Budaya }\end{array}$ & Kegiatan & Target Solusi & $\begin{array}{c}\text { Metode } \\
\text { Pelaksanaan } \\
\end{array}$ \\
\hline 1 & $\begin{array}{l}\text { Kesenian } \\
\text { Tari Reyog, } \\
\text { Jathilan, } \\
\text { Gajah- } \\
\text { gajahan, } \\
\text { Genongan, } \\
\text { dan } \\
\text { Tledekan. } \\
\end{array}$ & Regenerasi & $\begin{array}{l}\text { Merumuskan dan } \\
\text { mencetuskan } \\
\text { program regenerasi } \\
\text { yang konkrit untuk } \\
\text { jangka pendek, } \\
\text { menengah, dan } \\
\text { panjang. }\end{array}$ & $\begin{array}{l}\text { Melakukan FGD } \\
\text { dengan kelompok } \\
\text { seni, identifikasi } \\
\text { masalah, survei } \\
\text { kelompok umur, } \\
\text { dan melakukan FGD } \\
\text { dengan karang } \\
\text { taruna. }\end{array}$ \\
\hline 2 & $\begin{array}{l}\text { Kesenian } \\
\text { Tari Reyog, } \\
\text { Jathilan, } \\
\text { Gajah- } \\
\text { gajahan, } \\
\text { Genongan, }\end{array}$ & $\begin{array}{l}\text { Promosi } \\
\text { Budaya }\end{array}$ & $\begin{array}{l}\text { Memberikan } \\
\text { pelatihan kepada } \\
\text { kaum muda dan } \\
\text { taruna agar berperan } \\
\text { aktif dalam ikut ambil } \\
\text { bagian dalam }\end{array}$ & $\begin{array}{l}\text { Melakukan } \\
\text { pembicaraan } \\
\text { dengan stasiun } \\
\text { radio dan kelompok } \\
\text { usaha perhotelan } \\
\text { dan wisata, deal }\end{array}$ \\
\hline
\end{tabular}




\begin{tabular}{|c|c|c|c|c|}
\hline No & $\begin{array}{c}\text { Kelompok } \\
\text { Budaya }\end{array}$ & Kegiatan & Target Solusi & $\begin{array}{c}\text { Metode } \\
\text { Pelaksanaan }\end{array}$ \\
\hline & $\begin{array}{l}\text { dan } \\
\text { Tledekan. }\end{array}$ & & $\begin{array}{l}\text { mempromosikan } \\
\text { budaya daerah } \\
\text { melalui berbagai } \\
\text { macam jenis media } \\
\text { yang tersedia. }\end{array}$ & $\begin{array}{l}\text { kerjasama antara } \\
\text { kelompok seni } \\
\text { dengan stasiun } \\
\text { radion dan } \\
\text { kelompok usaha } \\
\text { perhotelan dan } \\
\text { wisata. } \\
\text { Melatih kaum } \\
\text { karang taruna } \\
\text { dalam } \\
\text { memanfaatkan } \\
\text { media sosial, } \\
\text { internet, dan massa } \\
\text { dalam } \\
\text { mempromosikan } \\
\text { kesenian budaya. } \\
\text { Membangun } \\
\text { website atau } \\
\text { mengaktifkan } \\
\text { kembali website } \\
\text { yang sudah ada } \\
\text { dengan menunjuk } \\
\text { penanggung jawab. }\end{array}$ \\
\hline & $\begin{array}{l}\text { Kesenian Alat } \\
\text { Musik Karawitan } \\
\text { dan Coke'an }\end{array}$ & $\begin{array}{l}\text { Kurikulum } \\
\text { Pembelajaran } \\
\text { dan } \\
\text { Pelatihan }\end{array}$ & $\begin{array}{l}\text { Merumuskan dan } \\
\text { mencetuskan } \\
\text { kurikulum } \\
\text { pendidikan kesenian } \\
\text { musik karawitan } \\
\text { dan coke'an } \\
\text { sehingga mudah } \\
\text { untuk dipahami dan } \\
\text { terdapat sasaran } \\
\text { target pencapaian } \\
\text { yang jelas serta } \\
\text { pendidikan kesenian } \\
\text { yang mudah untuk } \\
\text { dipelajari. }\end{array}$ & $\begin{array}{l}\text { Melakukan } \\
\text { pertemuan dengan } \\
\text { kelompok seni } \\
\text { dalam wadah FGD, } \\
\text { merumuskan } \\
\text { program } \\
\text { pendidikan } \\
\text { kesenian musik } \\
\text { yang konkrit untuk } \\
\text { jangka pendek, } \\
\text { menengah, dan } \\
\text { panjang. } \\
\text { Membantu } \\
\text { merumuskan } \\
\text { program pelatihan } \\
\text { keterampilan } \\
\text { mengajar efektif, } \\
\text { sehingga transfer } \\
\text { ilmu dapat berjalan } \\
\text { dengan lancar dan } \\
\text { menyenangkan. } \\
\text { Merumuskan } \\
\text { program sekolah } \\
\text { khusus kesenian }\end{array}$ \\
\hline
\end{tabular}




\begin{tabular}{|c|c|c|c|c|}
\hline No & $\begin{array}{l}\text { Kelompok } \\
\text { Budaya }\end{array}$ & Kegiatan & Target Solusi & $\begin{array}{c}\text { Metode } \\
\text { Pelaksanaan } \\
\end{array}$ \\
\hline & & & & $\begin{array}{l}\text { khas daerah } \\
\text { sehingga program } \\
\text { pendidikan tidak } \\
\text { saja sebagai } \\
\text { kegiatan } \\
\text { sampingan, } \\
\text { melainkan menjadi } \\
\text { program yang } \\
\text { terstruktur dan } \\
\text { terprogram secara } \\
\text { rapi sehingga } \\
\text { sasaran dan capaian } \\
\text { dapat teridentifikas } \\
\text { dengan jelas. }\end{array}$ \\
\hline 4 & $\begin{array}{l}\text { Kesenian Peran } \\
\text { Wayang Kulit }\end{array}$ & $\begin{array}{l}\text { Kurikulum } \\
\text { Pembelajaran } \\
\text { dan } \\
\text { Pelatihan }\end{array}$ & $\begin{array}{l}\text { Merumuskan dan } \\
\text { mencetuskan } \\
\text { kurikulum } \\
\text { pendidikan kesenian } \\
\text { peran wayang kulit } \\
\text { sehingga mudah } \\
\text { untuk dipahami dan } \\
\text { terdapat sasaran } \\
\text { target pencapaian } \\
\text { yang jelas serta } \\
\text { pendidikan kesenian } \\
\text { yang mudah untuk } \\
\text { dipelajari. }\end{array}$ & $\begin{array}{l}\text { Melakukan } \\
\text { pertemuan dengan } \\
\text { kelompok seni } \\
\text { dalam wadah FGD, } \\
\text { merumuskan } \\
\text { program } \\
\text { pendidikan } \\
\text { kesenian musik } \\
\text { yang konkrit untuk } \\
\text { jangka pendek, } \\
\text { menengah, dan } \\
\text { panjang. } \\
\text { Membantu } \\
\text { merumuskan } \\
\text { program pelatihan } \\
\text { keterampilan } \\
\text { mengajar efektif, } \\
\text { sehingga transfer } \\
\text { ilmu dapat berjalan } \\
\text { dengan lancar dan } \\
\text { menyenangkan. } \\
\\
\text { Merumuskan } \\
\text { program sekolah } \\
\text { khusus kesenian } \\
\text { khas daerah } \\
\text { sehingga program } \\
\text { pendidikan tidak } \\
\text { saja sebagai } \\
\text { kegiatan } \\
\text { sampingan, } \\
\text { melainkan menjadi } \\
\text { program yang } \\
\text { terstruktur dan } \\
\end{array}$ \\
\hline
\end{tabular}




\begin{tabular}{|c|c|c|c|c|}
\hline No & $\begin{array}{l}\text { Kelompok } \\
\text { Budaya }\end{array}$ & Kegiatan & Target Solusi & $\begin{array}{c}\text { Metode } \\
\text { Pelaksanaan }\end{array}$ \\
\hline & & & & $\begin{array}{l}\text { terprogram secara } \\
\text { rapi sehingga } \\
\text { sasaran dan capaian } \\
\text { dapat } \\
\text { teridentifikasi } \\
\text { dengan jalas. }\end{array}$ \\
\hline & $\begin{array}{l}\text { Kesenian } \\
\text { Musik } \\
\text { Campur } \\
\text { Sari }\end{array}$ & $\begin{array}{l}\text { Kurikulum } \\
\text { Pembelajaran } \\
\text { dan } \\
\text { Pelatihan }\end{array}$ & $\begin{array}{l}\text { Merumuskan dan } \\
\text { mencetuskan } \\
\text { kurikulum } \\
\text { pendidikan kesenian } \\
\text { musik campur sari } \\
\text { sehingga mudah } \\
\text { untuk dipahami dan } \\
\text { terdapat sasaran } \\
\text { target pencapaian } \\
\text { yang jelas serta } \\
\text { pendidikan kesenian } \\
\text { yang mudah untuk } \\
\text { dipelajari. }\end{array}$ & $\begin{array}{l}\text { Melakukan } \\
\text { pertemuan dengan } \\
\text { kelompok seni } \\
\text { dalam wadah FGD, } \\
\text { merumuskan } \\
\text { program } \\
\text { pendidikan } \\
\text { kesenian musik } \\
\text { yang konkrit untuk } \\
\text { jangka pendek, } \\
\text { menengah, dan } \\
\text { panjang. } \\
\\
\text { Merumuskan } \\
\text { program pelatihan } \\
\text { keterampilan } \\
\text { mengajar efektif, } \\
\text { sehingga transfer } \\
\text { ilmu dapat berjalan } \\
\text { dengan lancar dan } \\
\text { menyenangkan. } \\
\\
\text { Merumuskan } \\
\text { program sekolah } \\
\text { khusus kesenian } \\
\text { khas daerah } \\
\text { sehingga program } \\
\text { pendidikan tidak } \\
\text { saja sebagai } \\
\text { kegiatan } \\
\text { sampingan, } \\
\text { melainkan menjadi } \\
\text { program yang } \\
\text { terstruktur dan } \\
\text { terprogram secara } \\
\text { rapi sehingga } \\
\text { sasaran dan } \\
\text { capaian dapat } \\
\text { teridentifikasi } \\
\text { dengan jalas. }\end{array}$ \\
\hline 6 & $\begin{array}{l}\text { Upacara Adat } \\
\text { Metik Desa dan } \\
\text { Metri Tandur }\end{array}$ & $\begin{array}{l}\text { Organizer } \\
\text { dan Promosi } \\
\text { Gelaran } \\
\text { Budaya }\end{array}$ & $\begin{array}{l}\text { Melakukan pelatihan } \\
\text { keterampilan } \\
\text { organizer upacara } \\
\text { adat yang } \\
\text { professional sehingga } \\
\text { setiap upacara adat }\end{array}$ & $\begin{array}{l}\text { Melakukan } \\
\text { pertemuan dengan } \\
\text { kelompok seni } \\
\text { dalam wadah FGD } \\
\text { untuk merumuskan } \\
\text { SOP pelaksanaan }\end{array}$ \\
\hline
\end{tabular}




\begin{tabular}{|c|c|c|c|c|}
\hline No & $\begin{array}{c}\text { Kelompok } \\
\text { Budaya }\end{array}$ & Kegiatan & Target Solusi & $\begin{array}{c}\text { Metode } \\
\text { Pelaksanaan } \\
\end{array}$ \\
\hline & & & $\begin{array}{l}\text { dapat berjalan } \\
\text { dengan penuh } \\
\text { kesakralan dan } \\
\text { memiliki nilai seni } \\
\text { yang tinggi dimata } \\
\text { mereka yang datang } \\
\text { untuk } \\
\text { menyaksikannya. } \\
\text { Promosi gelaran } \\
\text { budaya maupun } \\
\text { upacara adat yang } \\
\text { masif dan } \\
\text { terstruktur sehingga } \\
\text { dapat mengundang }\end{array}$ & $\begin{array}{l}\text { upacara adat yang } \\
\text { terstandarisasi } \\
\text { dengan benar } \\
\text { sehingga mudah } \\
\text { untuk dipelajari } \\
\text { dan diturunkan } \\
\text { kegenerasi } \\
\text { berikutnya. } \\
\text { Standarisasi } \\
\text { upacara adat yang } \\
\text { sudah ditetapkan, } \\
\text { bisa dipakai untuk } \\
\text { panduan dalam } \\
\text { pelatihan organizer } \\
\text { gelaran budaya dan } \\
\text { upacara adat. } \\
\text { Membantu } \\
\text { menjembatani } \\
\text { kerjasama dengan } \\
\text { Pemerintah Daerah, } \\
\text { kelompok pelaku }\end{array}$ \\
\hline 7 & Tour Guide & $\begin{array}{l}\text { Pelayanan } \\
\text { Prima }\end{array}$ & $\begin{array}{l}\text { Mendokumentasikan } \\
\text { dan menstruktur } \\
\text { kebudayaan. Setiap } \\
\text { pemandu yang } \\
\text { ditugaskan harus } \\
\text { mempelajari dan } \\
\text { menguasai } \\
\text { pengetahuan dan } \\
\text { filosofi dari masing- } \\
\text { masing kebudayaan } \\
\text { yang ada. Setiap } \\
\text { tempat dan lokasi } \\
\text { diberikan petunjuk- } \\
\text { petunjuk yang jelas } \\
\text { sehingga memudahkan } \\
\text { untuk melakukan } \\
\text { kunjungan dari satu } \\
\text { tempat ke tempat lain. }\end{array}$ & $\begin{array}{l}\text { Melakukan FGD } \\
\text { dengan kelompok } \\
\text { pelaku seni dan } \\
\text { melakukan } \\
\text { dokumentasi } \\
\text { secara penuh } \\
\text { setiap potongan } \\
\text { sejarah dan filosofi } \\
\text { dari masing-masing } \\
\text { kebudayaan yang } \\
\text { ada. } \\
\text { Melakukan FGD } \\
\text { dan workshop } \\
\text { dengan para } \\
\text { pemandu yang } \\
\text { telah dipilih dan } \\
\text { ditunjuk desa } \\
\text { sebagai perwakilan } \\
\text { yang memandu } \\
\text { tamu dalam } \\
\text { mengenalkan } \\
\text { daerah dan } \\
\text { budayanya. }\end{array}$ \\
\hline 8 & $\begin{array}{l}\text { Keterampilan } \\
\text { Berbahasa } \\
\text { Asing (Bahasa } \\
\text { Inggris) }\end{array}$ & $\begin{array}{l}\text { Pelayanan } \\
\text { Prima }\end{array}$ & $\begin{array}{l}\text { Masyarakat diberikan } \\
\text { pendidikan dan } \\
\text { pelatihan berbahasa } \\
\text { asing. }\end{array}$ & $\begin{array}{l}\text { Melakukan beberapa } \\
\text { kali kelas intensif } \\
\text { dalam keterampilan } \\
\text { berbahasa Inggris } \\
\text { sehari-hari, dan } \\
\text { melakukan kelas } \\
\text { lanjutan untuk }\end{array}$ \\
\hline
\end{tabular}




\begin{tabular}{|c|l|l|l|l|}
\hline No & \multicolumn{1}{|c|}{$\begin{array}{c}\text { Kelompok } \\
\text { Budaya }\end{array}$} & Kegiatan & \multicolumn{1}{|c|}{ Target Solusi } & \multicolumn{1}{c|}{$\begin{array}{c}\text { Metode } \\
\text { Pelaksanaan }\end{array}$} \\
\hline 9 & $\begin{array}{l}\text { Keterampilan } \\
\text { Penyambutan } \\
\text { dan Mengurus } \\
\text { Guest House }\end{array}$ & $\begin{array}{l}\text { Pelayanan } \\
\text { Prima }\end{array}$ & $\begin{array}{l}\text { Masyarakat diberikan } \\
\text { pendidikan dan } \\
\text { pengetahuan tentang } \\
\text { berbagai macam } \\
\text { kebiasaan dan perilaku } \\
\text { tamu asing. }\end{array}$ & $\begin{array}{l}\text { Melakukan workshop } \\
\text { dan penyuluhan } \\
\text { bagaimana } \\
\text { menyambut tamu dan } \\
\text { mempelajari } \\
\text { kebiasaan dan } \\
\text { perilaku tamu-tamu } \\
\text { asing. Melatih } \\
\text { pemeliharaan rumah } \\
\text { contoh yang dijadikan } \\
\text { gemberikan } \\
\text { pelayanan terbaik. }\end{array}$ \\
\hline
\end{tabular}

(Sumber: Pelaksana kegiatan)

Pelaksanaan kegiatan yang dilaksanakan di Desa Plunturan Kecamatan Pulung Kabupaten Ponorogo dapat dibahas sebagai berikut :

1. Dengan melakukan penyuluhan umum tentang Urbanisasi.

a. Tim melakukan ceramah dengan memberikan motivasi dan dorongan agar warga mempunyai keinginan untuk memulai berwirausaha.

b. Tim melakukan survei dengan membagikan angket untuk meneliti dan menganalisa perkembangan pengetahuan audiens pasca penyuluhan.

c. Tim membuka kesempatan kepada audiens untuk melakukan konsultasi, baik untuk memulai usaha atau bagaimana mengembangkan usaha yang sudah ada.

d. Tim membagikan modul dan panduan untuk menjadi pegangan perangkat desa agar nantinya materi penyuluhan dapat tetap terpakai oleh warga selanjutnya.

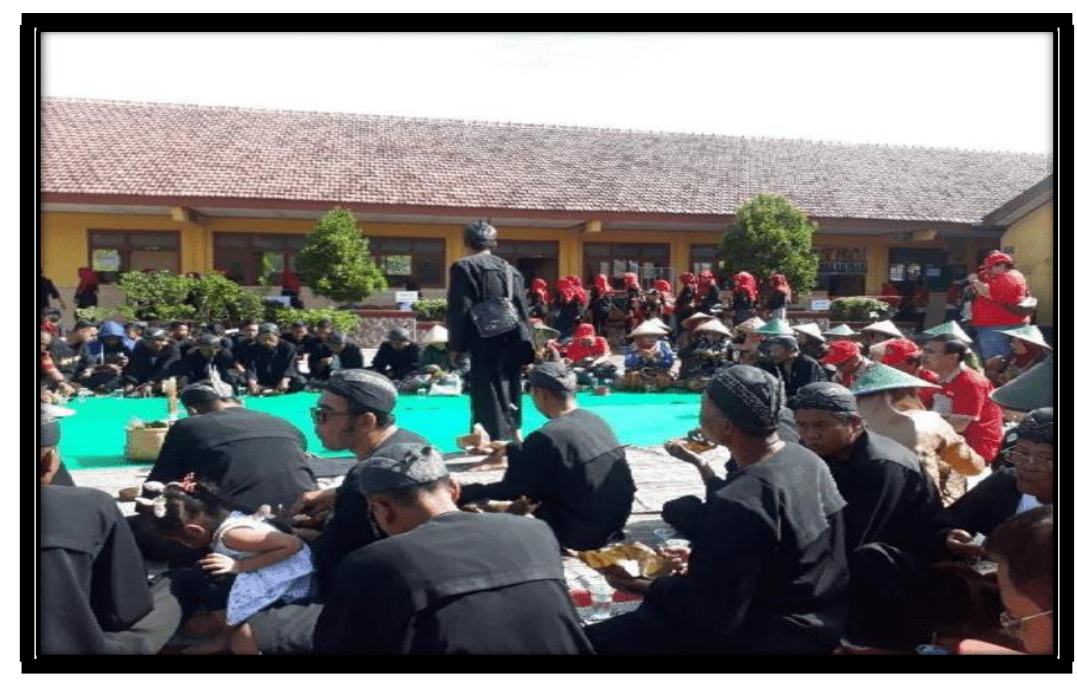

Gambar 1. Kenduri Metri Tandur Yang Diikuti Masyarakat Desa Plunturan

2. Melakukan peningkatan keterampilan

a. Tim melakukan peraga tentang keterampilan-keterampilan apa saja yang diperlukan oleh warga berkaitan dengan kehidupan sehari-hari.

b. Tim melakukan peraga tentang keterampilan-keterampilan apa saja yang diperlukan oleh warga berkaitan dengan kemampuan seni budaya. 
c. Tim membantu masyarakat dalam meningkatkan pengetahuan dan kemampuan dalam berbahasa Inggris.

d. Tim membantu masyarakat dalam meningkatkan keterampilan di rumah contoh sebagai bagian dari pelayanan "guest house" kepada turis asing yang akan berkunjung.

e. Tim membantu masyarakat dalam meningkatkan keterampilan dalam pelayanan prima sebagai "tour guide" untuk memandu turis asing mengenalkan budaya daerah.

f. Tim membantu masyarakat dalam meningkatkan keterampilan dalam memandu turis dan bagaimana menyampaikannya kepada turis asing dengan baik dan benar.

g. Tim melakukan peningkatan perbaikan taraf hidup layak masyarakat dengan menjaga kebersihan dan manajemen waktu.

h. Tim membantu paguyuban pelaku seni dalam mendorong warga untuk berpartisipasi dalam kegiatan-kegiatan pelatihan seni budaya.

i. Tim membantu pelaku dalam memasarkan dan mempromosikan kegiatan gebyar seni budaya.

j. Tim mengundang anak-anak, remaja, dan pemuda desa dalam berperan aktif belajar kesenian asli daerah.

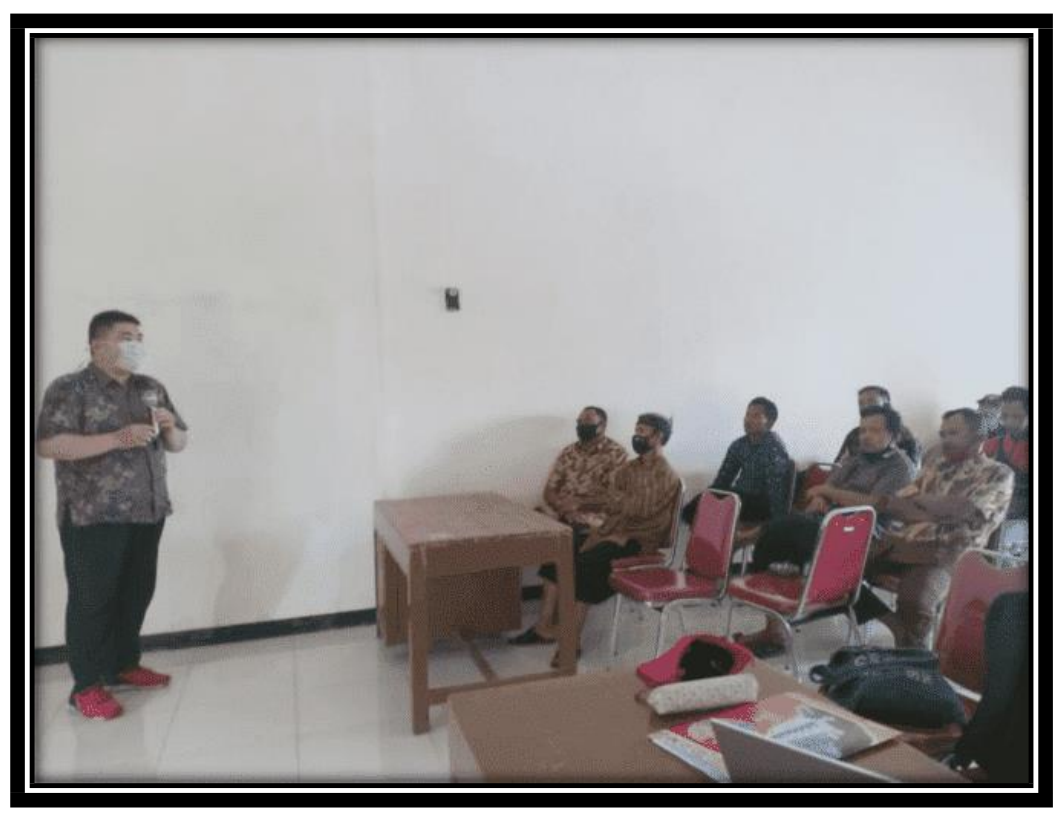

Gambar 2. Workshop Dengan Warga Dan Pelaku Seni

Dampak kegiatan yang dilaksanakan di Desa Plunturan Kecamatan Pulung Kabupaten Ponorogo adalah sebagai berikut :

1. Masyarakat mulai mengenal bahwa membuka diri terhadap orang asing bukan sebagai momok yang menakutkan.

2. Masyarakat termotivasi untuk terjun mengambil peranan untuk membantu desa menjadi desa wisata budaya.

3. Masyarakat termotivasi untuk mempromosikan budaya asli daerah dan ambil peranan dalam melakukan regenerasi kelompok pelaku seni budaya.

4. Masyarakat termotivasi untuk menjadi wirausahawan/wirausahawati yang mandiri dan kreatif.

5. Masyarakat mulai tahu bagaimana mengatasi kendala dan permasalahan yang dihadapi dalam memberikan pelayanan prima kepada turis asing.

6. Masyarakat memperoleh pengetahuan bagaimana mengelola "guest house" mereka 
dan mengembangkannya.

7. Masyarakat dibekali pengetahuan bagaimana melihat peluang dan merasakan hadirnya ancaman terhadap desa mereka.

8. Masyarakat dibekali keterampilan dalam melakukan riset dan menganalisa potensi daerah unggulan menjadi usaha unggulan.

9. Masyarakat dibekali keterampilan dan mengaplikasikan atau membuka usaha dan menjadi seorang enterpreneur sejati yang dapat menunjang pembangunan dan pengembangan desa.

10. Masyarakat dibekali keterampilan dalam berbahasa inggris, terutama anak-anak, remaja, dan pemuda desa.

11. Masyarakat dibekali keterampilan dalam berkomunikasi dan mengkomunikasikan daerah mereka kepada orang lain sebagai bagian dari desa wisata budaya.

Keberlanjutan kegiatan yang dilaksanakan di Desa Plunturan Kecamatan Pulung Kabupaten Ponorogo adalah sebagai berikut :

1. Mahasiswa yang memiliki minat untuk kembali ke Desa Plunturan diberi keleluasaan oleh desa dalam melakukan penelitian dan pengembangan kewirausahaan serta ambil bagian dalam pengembangan desa wisata lebihlanjut.

2. Masyarakat desa yang ingin dibantu dalam membangun dan mengembangkan usahanya diberikan keleluasaan untuk mengontaki Universitas 17 Agustus 1945 Surabaya untuk dibimbing lebih lanjut.

3. Masyarakat desa yang ingin dibantu dalam memasarkan produk-produk unggulan mereka, dapat difasilitasi oleh Universitas 17 Agustus 1945 Surabaya untuk menjadi mediator dalam memasarkan produk-produk lokal mereka.

4. Masyarakat desa yang terkendala dengan pembiayaan dapat menjalin kerjasama dengan Universitas 17 Agustus 1945 Surabaya dalam pendanaan pengembangan desa wisata budaya mereka.

5. Sampai pengabdian masyarakat selanjutnya, maka pihak desa akan terus mensosialisasikan dan melanjutkan trend positif ini demi mensejahterakan masyarakat desa.

6. Komunikasi antara pihak masyarakat Desa Plunturan dengan Universitas 17 Agustus 1945 Surabaya akan terus dibina dan dilanjutkan sampai kepada tahap implementasi lebih jauh.

\section{KESIMPULAN}

Melalui dilaksanakannya program desa wisata budaya di Desa Plunturan Kecamatan Pulung Kabupaten Ponorogo, dapat disimpulkan sebagai berikut :

1. Tim berhasil melaksanakan program dan mengadakan gebyar kebudayaan dengan dihadiri beberapa perwakilan dari pihak duta asing sebagai mitra untuk masa depan bagi pengembangan Desa Wisata Budaya di Desa Plunturan.

2. Tim berhasil menyatukan visi dan persepsi masyarakat desa sehingga mau perpartisipasi untuk sekarang dan masa depan dalam pengembangan Desa Wisata Budaya.

3. Kegiatan kewirausahaan yang dibutuhkan oleh masyarakat desa berhasil dilaksanakan dan mereka mau untuk ikut maju bergerak untuk membuka lapangan kerja baru yang berkaitan dengan kesenian budaya daerah.

4. Masyarakat desa dengan dibantu oleh Tim Mahasiswa Pengabdian Masyarakat Universitas 17 Agustus 1945 Surabaya dapat menjalin kerjasama dengan baik yang saling menguntungkan dan bermanfaat untuk mensejahterakan masyarakat desa. 
5. Dukungan perangkat desa yang sangat luar biasa, juga menjadi hal penting sehingga pelaksanaan sosialisasi berjalan dengan lancar dan tertib.

6. Dukungan perangkat desa yang luar biasa juga ditunjukkan dengan kemauan untuk memobilisasi masyarakat desa agar mau datang menghadiri acara sosialisasi/penyuluhan.

7. Kegiatan berjalan dengan sangat lancar tanpa hambatan adalah karena kerja keras Tim yang solid dan tertata rapi sehingga acara berjalan sukses dan undangan yang hadir merasa puas.

8. Dukungan dari pihak Universitas 17 Agustus 1945 Surabaya melalui LPPM juga banyak membantu terlaksananya acara ini, mulai dari pendanaan dan dukungan administratif yang cepat.

9. Pelaksanaan kegiatan mampu memberikan sumbangsih berharga bagi masyarakat desa dan juga Tim pelaksana kegiatan.

10. Antara Desa Plunturan dengan Universitas 17 Agustus 1945 Surabaya makin terjalin hubungan yang hangat dan harmonis dengan harapan kedepannya hubungan ini dapat terus dilanjutkan oleh tim-tim berikutnya.

\section{DAFTAR PUSTAKA}

Irawati, N., \& Priyanto, S., E. (2018). Strategi Pengelolaan dan Pengembangan Desa Budaya di Yogyakarta. Prosiding Seminar Nasional Struktural. Yokyakarta.

Moertopo, A. (1978). Strategi Kebudayaan, Centre for Strategic, and International Studies (CSIS). Jakarta.

Putti, J. M., \& Audrey C. (1990). Culture and Management : A Case Book. Singapore : Mc. Graw Hill Book Co.

Peursen, V. (1988). Strategi Kebudayaan. Yogyakarta : Kanisius. Larasan. Bali.

Antara Made. (2015). Pengelolaan Pariwisata Berbasis Potensi Lokal. Pustaka Persada.

A.J, Muljadi. (2012). Kepariwisataan dan Perjalanan. Jakarta: Raja Grafindo

Demartoto Argyo. (2009). Pembangunan Pariwisata Berbasis Masyarakat. Sebelas Maret University Press. Surakarta.

Komariah, Neneng \& Saepudin, Encang \& Yusup, Pawit. (2018). Pengembangan

Desa Wisata Berbasis Kearifan Lokal. Jurnal Pariwisata Pesona. 3. 10.26905/jpp.v3i2.2340.

Rahmatillah, Tri \& Insyan, Osy \& Nurafifah, Nurafifah \& Hirsan, Fariz. (2019). Strategi Pengembangan Desa Wisata Berbasis Wisata Alam dan Budaya Sebagai Media Promosi Desa Sangiang. Jurnal Planoearth. 4. 111. 10.31764/jpe.v4i2.970.

Ambo Rappe, Rohani \& Mappangara, Suriadi \& Ukkas, Marzuki \& Faizal, Akhmad \& Gatta, Ratnawati \& Andriani, Irma. (2018). Strategi Promosi Dalam Pengembangan Desa Wisata Budaya Berbasis Masyarakat Di Desa Sanrobone, Kecamatan Sanrobone, Kabupaten Takalar. 9. 280-293.

Widyaningsih, Heni. (2019). Pemberdayaan Masyarakat Dalam Pengembangan Desa Wisata Dan Implikasinya Terhadap Sosial Budaya Di Desa Sendangagung, Minggir, Sleman. Journal of Indonesian Tourism, Hospitality and Recreation. 2. 10.17509/jithor.v2i1.16433. 